\title{
Synthesis and Thermal Behavior of Side-Chain Liquid Crystalline Aziridine Oligomers
}

\author{
Yusuke Kawakami, ${ }^{\dagger}$ Masaki Baba, Yasunori Murate, ${ }^{*}$ Hideo Kunisada, ${ }^{*}$ \\ and Yasuo YUKI*
Graduate School of Materials Science, Japan Advanced Institute of Science and Technology, Asahidai 1-1, Tatsunokuchi, Ishikawa 923-12
* Department of Materials Science and Engineering, Nagoya Institute of Technology, \\ Gokiso, Showa 466, Nagoya
}

(Received April 10, 1996)

\begin{abstract}
KEY WORDS Aziridine / Cationic Polymerization / Polymer Structure / Thermal Analysis / Liquid Crystalline Oligomer / Nematic /
\end{abstract}

Polysiloxanes, polyacrylates, and polymethacrylates are common main-chain components ${ }^{1-9}$ of side-chain liquid crystalline polymers. Examples of other mainchain are rather limited ${ }^{10-28}$. We reported two new types of liquid crystalline polymers with polyoxetane $^{23-25}$ or polydiene $e^{29-31}$ main-chain, in which importance of flexibility of the main chain was strongly suggested. In designing the flexible main chain, introduction of a heteroatom is an attractive method. Furtheremore, the heteroatom may create tacticity at $\alpha$-carbon next to it in the main chain. It is of interest to study the effects of stereoregularity or chirality of polymer backbone on the liquid crystalline phase. Percec, ${ }^{19}$ Shibaev, ${ }^{20}$ and Nagase $^{21}$ reported liquid crystalline polyethers obtained by cationic polymerization of optically active epoxide with mesogenic group. However, since the sterochemistry of main chain was not well-defined a definite conclusion could not be drawn about the effects of stereoregularity on the liquid crystalline state. Spassky ${ }^{22}$ discussed the influence of backbone chirality on the liquid crystalline phase of the anionically-formed polymer.

Nitrogen atom also creates a similar situation as oxygen in the backbone. Ujiie reported liquid crystalline poly(ethylenimine) $\mathrm{s}^{26-28}$ obtained from commercial poly(ethylenimine). Since poly(ethylenimine) contains not only the secondary amino group but also primary and tertiary amino groups, it is unknown whether poly(iminoethylene) can act as a good main chain component of side-chain liquid crystalline polymers.

This article reports our preliminary approach to the synthesis of well-defined oligo(aziridine)s by using a well-defined monomer and modification of polymers of interest for the response to stimuli by an electric field.

\section{EXPERIMENTAL}

\section{General}

${ }^{1} \mathrm{H}$ NMR spectra were obtained on a Varian $200 \mathrm{MHz}$ NMR spectrometer Model Gemini 200. Chemical shifts are given in ppm from TMS in $\mathrm{CDCl}_{3}$. Molecular weight analysis was carried out on a Tosoh (TSK) GPC Model

\footnotetext{
† To whom correspondence should be addressed.
}

HLC 802 equipped with TSK gels G3000H (exclusion molecular weight, polystyrene $6 \times 10^{4}$ ) and $\mathrm{G} 5000 \mathrm{H}$ (exclusion molecular weight, polystyrene $4 \times 10^{6}$ ), using chloroform as an eluent at $1 \mathrm{~mL} \mathrm{~min}^{-1}$. DSC analyses were carried out on a SEIKO thermal analysis system Model SSC 5500 with heating or cooling rate $5^{\circ} \mathrm{C} \mathrm{min}-1$ unless otherwise noted. The transition temperature is given where the transition started. Optical polarization micrographs were taken on a Nikon optical polarization micrograph Model OPTIPHOTO-POL equipped with a Mettler FP82 hot stage.

\section{Synthesis}

The synthetic outline is shown in Scheme 1. The names

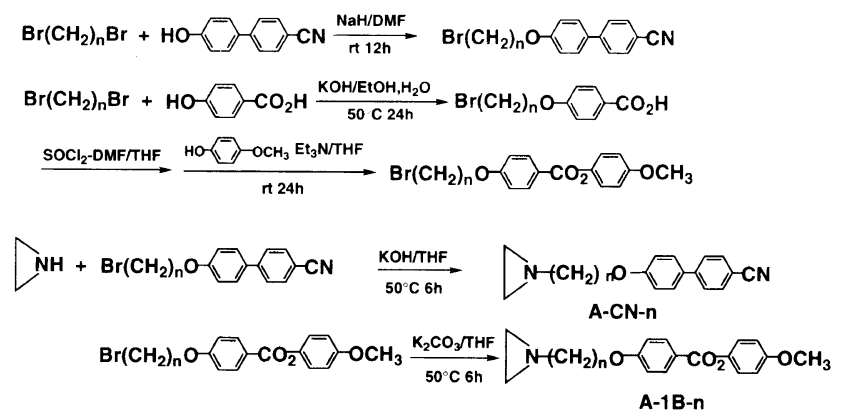

Scheme 1. Synthesis of monomers.

of the monomers are abbreviated by the combination of A indicating aziridine; the abbreviated name of the mesogen: $\mathrm{CN}$ for cyanobiphenyl, 1B for methoxyphenyl benzoate; and the spacer: 4 for tetramethylene, 5 for pentamethylene, and 6 for hexamethylene. The protons of the monomers and polymers are indicated in Figure 1.
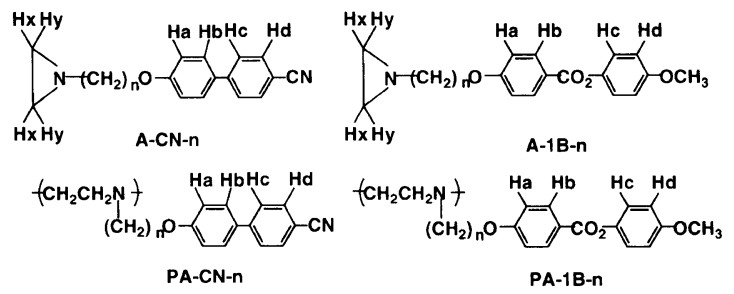

Figure 1. Names and indication of protons of the monomers and the polymers. 
4-Cyano-4'-( $\omega$-bromoalkyloxy)biphenyls were synthesized similarly to the reported method. ${ }^{24}$ 4-Cyano-4'-(4bromobutoxy)biphenyl $\left(74 \%, \mathrm{mp} 63^{\circ} \mathrm{C}\right)$, 4-cyano-4'-(5bromopentyloxy)biphenyl $\left(69 \%, \mathrm{mp} 79^{\circ} \mathrm{C}\right)$, and 4-cyano$4^{\prime}$-(6-bromohexyloxy)biphenyl $\left(81 \%, \mathrm{mp} 67^{\circ} \mathrm{C}\right)$ gave resonable elemental and NMR analysis results.

$N$ - $\left\{\left(4-C y a n o b i p h e n y l-4^{\prime}-y\right.\right.$ loxy $)$ butyl $\}$ aziridine $(A-C N$ 4)

To a mixture of $50 \mathrm{w} / \mathrm{w} \%$ aqueous $\mathrm{KOH}(50 \mathrm{~mL})$ and aziridine $(4.3 \mathrm{~g}, 100 \mathrm{mmol})$ in tetrahydrofuran (THF) $(100 \mathrm{~mL})$ was added 4-cyano-4'-(4-bromobutoxy)biphenyl $(33.0 \mathrm{~g}, 100 \mathrm{mmol})$ in THF $(50 \mathrm{~mL})$. The mixture was stirred at $50^{\circ} \mathrm{C}$ for $6 \mathrm{~h}$, and unreacted aziridine and excess THF were distilled. Aqueous phase was extracted with chloroform $(40 \mathrm{~mL} \times 3)$, and the combined organic layer was washed with water $(30 \mathrm{~mL})$ and dried over anhydrous magnesium sulfate. Removal of the solvent followed by short path column chromatography on alumina gel (hexane-chloroform-ether $=2: 1: 1$ ) afforded crude product, which was purified by recrystallization from dichloromethane and hexane mixed solvent (1: 1). Yield $71 \%$. mp $86^{\circ} \mathrm{C}$. Calcd for $\mathrm{C}_{19} \mathrm{H}_{20} \mathrm{ON}_{2}$ : C, $78.1 \% ; \mathrm{H}, 6.89 \%$; N, 9.58\%. Found: C, 78.2\%; H, $6.99 \% ; \mathrm{N}, 9.33 \%$. Chemical shifts: $1.08,1.72$ (two d, $2 \mathrm{H}$ each, $\left.J=3.1 \mathrm{~Hz}, \mathrm{H}_{x}, \mathrm{H}_{y}\right), 1.75\left(\mathrm{~m}, 2 \mathrm{H}, \mathrm{NCH}_{2} \mathrm{CH}_{2}\right)$, $1.90\left(\mathrm{~m}, 2 \mathrm{H}, \mathrm{CH}_{2} \mathrm{CH}_{2} \mathrm{O}\right), 2.26\left(\mathrm{t}, 2 \mathrm{H}, J=6.0 \mathrm{~Hz}, \mathrm{CH}_{2} \mathrm{~N}\right)$, $4.03\left(\mathrm{t}, 2 \mathrm{H}, J=6.0 \mathrm{~Hz}, \mathrm{CH}_{2} \mathrm{O}\right), 7.00(\mathrm{~d}, 2 \mathrm{H}, J=8.8 \mathrm{~Hz}$, $\left.H_{\mathrm{a}}\right), 7.56\left(\mathrm{~d}, 2 \mathrm{H}, J=8.8 \mathrm{~Hz}, H_{\mathrm{b}}\right), 7.76(\mathrm{~d}, 4 \mathrm{H}, J=8.8 \mathrm{~Hz}$, $\left.H_{\mathrm{c}}, H_{\mathrm{d}}\right)$.

$N$-\{(4-Cyanobiphenyl-4'-yloxy)pentyl $\}$ aziridine (A$\mathrm{CN}-5)\left(71 \%, \mathrm{mp} 97^{\circ} \mathrm{C}\right)$ and $N-\{$ (4-cyanobiphenyl-4'yloxy)hexyl aziridine (A-CN-6) $\left(39 \%, \mathrm{mp} 71^{\circ} \mathrm{C}\right)$ also gave reasonable analytical results.

4-( $\omega$-Bromoalkyloxy)benzoic acids

These compounds were synthesized from 4-hydroxybenzoic acid (13.8 g, $100 \mathrm{mmol})$ and $1, \omega$-dibromoalkane $(100 \mathrm{mmol})$ in aqueous ethanol $(300: 850 \mathrm{~mL})$ containing potassium hydroxide $(16.8 \mathrm{~g}, 300 \mathrm{mmol})$ at $50^{\circ} \mathrm{C}$ for $24 \mathrm{~h}$. Ethanol was distilled in keeping the volume at about $600 \mathrm{~mL}$ by the succesive addition of $5 \mathrm{wt} \%$ aqueous sodium carbonate (about $400 \mathrm{~mL}$ ). After excess $1, \omega$-dibromoalkane was separated, the residue was washed with dichlomethane and neutralized with $1 \mathrm{~N}$ hydrochloric acid. The formed precipitate with foaming was collected and washed thououghly with cold water, and purified by recrystallization from methanol-water. Yield 43\%. Calcd for $\mathrm{C}_{11} \mathrm{H}_{13} \mathrm{O}_{3} \mathrm{Br}$ : C, 48.4\%; H, 4.80\%. Found: $\mathrm{C}, 48.5 \%$; H, 4.71\%. Chemical shifts (DMSO$\left.d_{6}\right): 2.05\left(\mathrm{~m}, 4 \mathrm{H}, \mathrm{CH}_{2} \mathrm{CH}_{2} \mathrm{CH}_{2} \mathrm{CH}_{2}\right), 3.62(\mathrm{t}, 2 \mathrm{H}, J=$ $\left.6.4 \mathrm{~Hz}, \mathrm{CH}_{2} \mathrm{Br}\right), 4.10\left(\mathrm{t}, 2 \mathrm{H}, J=6.0 \mathrm{~Hz}, \mathrm{CH}_{2} \mathrm{O}\right), 6.99$ $\left(\mathrm{d}, 2 \mathrm{H}, J=7.5 \mathrm{~Hz}, H_{\mathrm{a}}\right), 7.89\left(\mathrm{~d}, 2 \mathrm{H}, J=7.5 \mathrm{~Hz}, H_{\mathrm{b}}\right)$.

4- $(\omega$-Bromoalkoxy)benzoic acid $(50 \mathrm{mmol})$ was converted to acid chloride and transformed into 4-methoxyphneyl ester by the reaction with 4-methoxyphenol $(7.5 \mathrm{~g}, 60 \mathrm{mmol})$. The produced ester was isolated by silica gel column chromatography.

4-Methoxyphenyl 4-(4-Bromobutoxy)benzoate

Yield $44 \%$. mp $98^{\circ} \mathrm{C}$. Calcd for $\mathrm{C}_{18} \mathrm{H}_{19} \mathrm{O}_{4} \mathrm{Br}$ : C, $57.0 \% ; \mathrm{H}, 5.05 \%$. Found: C, $57.9 \% ; \mathrm{H}, 5.27 \%$. Chemical shifts: $3.81\left(\mathrm{~s}, 3 \mathrm{H}, \mathrm{OCH}_{3}\right), 6.92\left(\mathrm{~d}, 2 \mathrm{H}, J=7.5 \mathrm{~Hz}, H_{\mathrm{d}}\right)$, $6.96\left(\mathrm{~d}, 2 \mathrm{H}, J=7.5 \mathrm{~Hz}, H_{\mathrm{a}}\right), 7.12\left(\mathrm{~d}, 2 \mathrm{H}, J=7.5 \mathrm{~Hz}, H_{\mathrm{c}}\right)$, $8.13\left(\mathrm{~d}, 2 \mathrm{H}, J=7.5 \mathrm{~Hz}, H_{\mathrm{b}}\right)$.

4-(5-Bromopentyloxy)benzoic acid (53\%), 4-(6-bro- mohexyloxy)benzoic acid $(60 \%)$, 4-methoxyphenyl 4-(5bromopentyloxy)benzoate $\left(50 \%, \mathrm{mp} 85^{\circ} \mathrm{C}\right), 4$-methoxyphenyl 4-(6-bromohexyloxy)benzoate $\left(54 \%, \mathrm{mp} 81^{\circ} \mathrm{C}\right)$ gave resonable analytical data.

$N$-[4-\{4-(4-Methoxyphenyl-4'-yloxycarbonyl)phenyl4'-yloxy\}butylaziridine $(A-1 B-4)$

A-1B-4 was synthesized similarly with A-CN-4 using $\mathrm{K}_{2} \mathrm{CO}_{3}(27.6 \mathrm{~g}, 200 \mathrm{mmol})$ and 4-methoxyphenyl 4-(4bromobutoxy)benzoate $(37.9 \mathrm{~g}, 100 \mathrm{mmol})$. Yield $22 \%$. mp $107^{\circ}$ C. Calcd for $\mathrm{C}_{20} \mathrm{H}_{23} \mathrm{O}_{4} \mathrm{~N}$ : C, $70.4 \% ; \mathrm{H}, 6.79 \%$; $\mathrm{N}, 4.10 \%$. Found: $\mathrm{C}, 70.6 \% ; \mathrm{H}, 7.00 \%, \mathrm{~N}, 3.76 \%$. Chemical shifts: $1.09,1.72$ (two d, $2 \mathrm{H}$ each, $J=3.1$ $\left.\mathrm{Hz}, \mathrm{H}_{x}, \mathrm{H}_{y}\right), 1.75\left(\mathrm{~m}, 2 \mathrm{H}, \mathrm{NCH}_{2} \mathrm{CH}_{2}\right), 1.90(\mathrm{~m}, 2 \mathrm{H}$, $\left.\mathrm{CH}_{2} \mathrm{CH}_{2} \mathrm{O}\right), 2.26\left(\mathrm{t}, 2 \mathrm{H}, \mathrm{J}=6.0 \mathrm{~Hz}, \mathrm{CH}_{2} \mathrm{~N}\right), 3.78(\mathrm{~s}, 3 \mathrm{H}$, $\left.\mathrm{OCH}_{3}\right), 4.07\left(\mathrm{t}, 2 \mathrm{H}, \mathrm{J}=6.0 \mathrm{~Hz}, \mathrm{CH}_{2} \mathrm{O}\right), 6.91(\mathrm{~d}, 2 \mathrm{H}$, $\left.J=7.5 \mathrm{~Hz}, H_{\mathrm{d}}\right), 6.95\left(\mathrm{~d}, 2 \mathrm{H}, J=8.8 \mathrm{~Hz}, H_{\mathrm{a}}\right), 7.12(\mathrm{~d}, 2 \mathrm{H}$, $\left.J=7.5 \mathrm{~Hz}, H_{\mathrm{c}}\right), 8.14\left(\mathrm{~d}, 2 \mathrm{H}, J=8.8 \mathrm{~Hz}, H_{\mathrm{b}}\right)$.

$N$-[5-\{4-(4-Methoxyphenyl-4'-yloxycarbonyl )phenyl$4^{\prime}$-yloxy pentyl]aziridine (A-1B-5) $\left(16 \%, \mathrm{mp} 69^{\circ} \mathrm{C}\right), \mathrm{N}$ [6-\{4-(4-methoxyphenyl-4'-yloxycarbonyl)phenyl-4' yloxy $\}$ hexyl]aziridine (A-1B-6) $\left(52 \%, \mathrm{mp} 72^{\circ} \mathrm{C}\right)$ also gave reasonable analytical data.

\section{Polymerization}

Monomers were dried under vacuum at $60^{\circ} \mathrm{C}$ for 1 day after purification. Polymerization was carried out in dry dichloromethane using boron trifluoride ether complex $\left(\mathrm{BF}_{3} \cdot \mathrm{OEt}_{2}\right)$ or triethyloxonium tetrafluoroborate $\left(\mathrm{Et}_{3} \mathrm{O}^{+} \mathrm{BF}_{4}^{-}\right)$with the concentration of $[\mathrm{M}]$ at $1.0 \mathrm{~mol}$ $\mathrm{mL}^{-1}$. The polymers formed were recovered by precipitation in hexane. The crude product was dissolved in THF, and precipitated into $1 \mathrm{wt} \%$ aquous sodium hydrogen carbonate. The precipitate was again dissolved in THF, and insoluble material was removed by filtration, and precipitated into hexane. The crude polymer thus obtained was purified by repeated reprecipitation from THF into hexane. The absence of monomer in polymerization product was checked by thin-layer chromatography and GPC.

The names of polymers are abbreviated by the combination of $P$ and the abbreviated name of the monomer. For an example, poly $(\mathrm{A}-\mathrm{CN}-6)$ is abbreviated as PA-CN-6 as shown in Figure 1.

PA-CN-4[Chemical shifts: $1.5-1.7\left(\mathrm{~m}, 2 \mathrm{H}, \mathrm{NCH}_{2}-\right.$ $\left.\mathrm{CH}_{2}\right), 1.7-1.9\left(\mathrm{~m}, 2 \mathrm{H}, \mathrm{OCH}_{2} \mathrm{CH}_{2}\right), 2.3-2.7(\mathrm{~m}, 6 \mathrm{H}$, $\left.\mathrm{NCH}_{2}\right), 3.90\left(\mathrm{t}, 2 \mathrm{H}, J=6.0 \mathrm{~Hz}, \mathrm{OCH}_{2}\right), 6.86(\mathrm{~d}, 2 \mathrm{H}$, $\left.J=8.8 \mathrm{~Hz}, H_{\mathrm{a}}\right), 7.40\left(\mathrm{~d}, 2 \mathrm{H}, J=8.8 \mathrm{~Hz}, H_{\mathrm{b}}\right), 7.49(\mathrm{~d}, 2 \mathrm{H}$, $\left.\left.J=7.8 \mathrm{~Hz}, H_{\mathrm{c}}\right), 7.57\left(\mathrm{~d}, 2 \mathrm{H}, J=7.8 \mathrm{~Hz}, H_{\mathrm{d}}\right)\right]$, PA-CN-5, PA-CN-6, and PA-1B-4 [Chemical shifts: 1.5-1.7 (m, $\left.2 \mathrm{H}, \mathrm{NCH}_{2} \mathrm{CH}_{2}\right), 1.7-1.9\left(\mathrm{~m}, 2 \mathrm{H}, \mathrm{OCH}_{2} \mathrm{CH}_{2}\right), 2.3-2.7$ $\left(\mathrm{m}, 6 \mathrm{H}, \mathrm{NCH}_{2}\right), 3.75\left(\mathrm{~s}, 3 \mathrm{H}, \mathrm{OCH}_{3}\right), 3.95(\mathrm{t}, 2 \mathrm{H}$, $J=6.0 \mathrm{~Hz}), 6.85\left(\mathrm{~d}, 2 \mathrm{H}, J=8.8 \mathrm{~Hz}, H_{\mathrm{d}}\right), 6.87(\mathrm{~d}, 2 \mathrm{H}$, $\left.J=7.5 \mathrm{~Hz}, H_{\mathrm{a}}\right), 7.03\left(\mathrm{~d}, 2 \mathrm{H}, J=8.8 \mathrm{~Hz}, H_{\mathrm{c}}\right), 8.04(\mathrm{~d}, 2 \mathrm{H}$, $\left.\left.J=7.5 \mathrm{~Hz}, H_{\mathrm{b}}\right)\right]$, PA-1B-5, PA-1B-6 gave reasonble NMR data.

Linear PA-CN-4 (LPA-CN-4) was obtained by alkylation of linear polyaziridine $(0.10 \mathrm{~g})^{32,33}$ with 4-cyano4'-(4-bromobutoxy)biphenyl $(0.77 \mathrm{~g}, 2.3 \mathrm{mmol})$ in the presence of potassium carbonate $(0.32 \mathrm{~g}, 2.3 \mathrm{mmol})$ in acetonitrile and THF mixed solvent $(30: 30 \mathrm{~mL})$ under reflux of the solvent for $100 \mathrm{~h}$. The product was recovered as a precipitate by pouring into hexane $(200 \mathrm{~mL})$. The product was dissolved in THF, and poured into water 
containing $1 \mathrm{wt} \%$ sodium hydrogen carbonate. The precipitated polymer was recovered, and purified by repeated reprecipitaion from $\mathrm{THF}$ into hexane. Yield $30 \%$. Calcd for $\mathrm{C}_{19} \mathrm{H}_{20} \mathrm{~N}_{2} \mathrm{O}: \mathrm{C}, 78.1 \% ; \mathrm{H}, 6.89 \% ; \mathrm{N}$, $9.58 \%$. Found: C, $74.7 \% ; \mathrm{H}, 7.48 \% ; \mathrm{N}, 10.4 \% ; \mathrm{Br}$, $1.66 \%$.

PA-1B-4 (528 mg) was quarternized (QPA-1B-4) with hydrobromic acid $\left(0.025 \mathrm{~mol} \mathrm{~L}^{-1}, 6.2 \mathrm{~mL}\right)$ in THF $(30$ $\mathrm{mL}$ ) at room temperature for $24 \mathrm{~h}$ under stirring. The reaction mixture was poured into hexane $(100 \mathrm{~mL})$, and the precipitated polymer was washed with methanol, followed by water until the washes became neutral. The polymer was recovered and dried in vacuo. Yield $90 \%$. Calcd for $\mathrm{C}_{20} \mathrm{H}_{24} \mathrm{NBrO}_{4}: \mathrm{C}, 56.9 \% ; \mathrm{H}, 5.73 \% ; \mathrm{N}$, $3.32 \%$; Br, $18.9 \%$. Found: C, 62.2\%; H, 6.18\%; N, $3.39 \% ; \mathrm{Br}, 13.0 \%$.

\section{RESULTS AND DISCUSSION}

\section{Synthesis}

Dropwise addition of the solution of the sodium salt of 4-cyano-4'-hydroxybiphenyl to $\alpha, \omega$-dibromoalkane prevented the formation of the bis-substituted derivative in the synthesis of 4-cyano-4'-( $\omega$-bromoalkyloxy)biphenyl. In the synthesis of A-CN- $n$, the presence of an alkali was essential to prevent cationic polymerization of the aziridine. In the analysis of monomers in HPLC using ODS (octadecyldimethylsilylated silica gel) column, the addition of anmonia to eluting solvent $\left(0.1 \mathrm{~mol} \mathrm{~L}^{-1}\right.$ ammmonia solution of water-methanol) was crucial for good separation. In the synthesis of 4 - $(\omega$-bromoalkyloxy)benzoic acid, the concentration of 4-hydroxybenzoate was $0.1 \mathrm{~mol} \mathrm{~L}^{-1}$ with three-times excess potassium hydroxide, and ethanol was used as little as possible for keeping homogeniety of the system so that the formation of $\omega$-bromoalkyl 4-hydroxybenzoate or $\omega$-ethoxyalkyl benzoate was minimized. In the synthesis of monomer
A-1B- $n$, potassium carbonate was best to avoid undesired cleavage of the ester function of 4-methoxyphenyl 4$(\omega$-bromoalkyloxy)benzoate.

It is worthwhile to point out that the protons of aziridine ring $\left(\mathrm{H}_{x}\right.$ and $\left.\mathrm{H}_{y}\right)$ of A-CN- $n$ or A-1B- $n$ appeared at different positions in solution at $25^{\circ} \mathrm{C}$. Bottini reported that ring methylene protons of $N$-ethylaziridine absorbed at around 1.10 and $1.70 \mathrm{ppm}$ at $25^{\circ} \mathrm{C}$. The peaks collapsed into a single peak at $120^{\circ} \mathrm{C}$, indicating rapid inversion of configuration of nitrogen atom at this temperature. $^{34}$ The aziridine protons of A-CN-4 did not collapse into one peak even at $120^{\circ} \mathrm{C}$. Inversion of the configuration of the nitrogen atom of the monomer seems much slower compared to $N$-ethylaziridine.

\section{Polymerization}

The results of the polymerization reactions are shown in Table I.

Goethals reported that a bulky substituent on the nitrogen atom, the presence of polar group in the substituent, and higher concentration of the monomer gave a good living nature of the polymerization by $\mathrm{Et}_{3} \mathrm{O}^{+} \mathrm{BF}_{4}^{-} \cdot{ }^{35} \mathrm{Et}_{3} \mathrm{O}^{+} \mathrm{BF}_{4}^{-}$gave rather poor results in this study, while $\mathrm{BF}_{3} \cdot \mathrm{OEt}_{2}$ showed higher activity. Nevertheless, the polymerization reactions were very slow and took almost 10 days to achieve quantitative conversion of the monomers. Although higher concentrations of aziridine monomers should be advantageous to avoid cyclic oligomer formation, the solubility of the monomers was not high enough $\left(1.0 \mathrm{~mol} \mathrm{~L}^{-1}\right)$. The weight average molecular weights of polymer were 1.1 to $8.0 \times$ $10^{3}\left(M_{w} / M_{n}=1.2-1.9\right)$. Molecular weight did not necessarily increase in proportion to the conversion or monomer to initiator ratio. Some chain transfer reactions might have occurred.

Table I. Polymerization of A-CN- $n$ and A-1B- $n$ in $\mathrm{CH}_{2} \mathrm{Cl}_{2}$

\begin{tabular}{|c|c|c|c|c|c|c|c|c|}
\hline \multirow{2}{*}{ Run } & \multirow{2}{*}{ Monomer } & \multirow{2}{*}{ Initiator } & \multirow{2}{*}{ Temp } & \multirow{2}{*}{$\frac{\text { time }}{\mathrm{h}}$} & \multirow{2}{*}{$\frac{\text { Conv. }}{\%}$} & \multicolumn{3}{|c|}{ GPC } \\
\hline & & & & & & $M_{w} / 10^{3}$ & $M_{n} / 10^{3}$ & $M_{w} / M_{n}$ \\
\hline 1 & \multirow[t]{6}{*}{ A-CN-4 } & \multirow{6}{*}{$\begin{array}{c}\mathrm{Et}_{3} \mathrm{O}^{+} \mathrm{BF}_{4}^{-} \\
\mathrm{BF}_{3} \mathrm{OEt}_{2}\end{array}$} & r.t. ${ }^{b}$ & 96 & 24 & 1.8 & 0.6 & 2.9 \\
\hline 2 & & & $0^{\circ} \mathrm{C}$ & 240 & 6.2 & 1.6 & 1.1 & 1.4 \\
\hline 3 & & & r.t. & 24 & 17 & 2.1 & 1.6 & 1.3 \\
\hline 4 & & & r.t. & 96 & 48 & 2.2 & 1.4 & 1.6 \\
\hline 5 & & & r.t. & 240 & 96 & 2.9 & 1.7 & 1.7 \\
\hline 6 & & & $120^{\circ} \mathrm{C}$ & 12 & 2 & 2.0 & 1.5 & 1.4 \\
\hline 7 & \multirow[t]{2}{*}{ A-CN-5 } & \multirow{2}{*}{$\begin{array}{c}\mathrm{Et}_{3} \mathrm{O}^{+} \mathrm{BF}_{4}^{-} \\
\mathrm{BF}_{3} \mathrm{OEt}_{2}\end{array}$} & r.t. & 96 & 89 & 1.1 & 0.9 & 1.2 \\
\hline 8 & & & r.t. & 96 & 75 & 5.7 & 3.9 & 1.5 \\
\hline 9 & \multirow[t]{3}{*}{ A-CN-6 } & \multirow[t]{3}{*}{$\mathrm{BF}_{3} \mathrm{OEt}_{2}$} & $0^{\circ} \mathrm{C}$ & 240 & 5.2 & 2.0 & 1.5 & 1.4 \\
\hline 10 & & & r.t. & 96 & 75 & 2.4 & 1.8 & 1.3 \\
\hline 11 & & & r.t. & 240 & 94 & 3.6 & 2.5 & 1.4 \\
\hline 12 & \multirow[t]{3}{*}{ A-1B-4 } & \multirow[t]{3}{*}{$\mathrm{BF}_{3} \mathrm{OEt}_{2}$} & $0^{\circ} \mathrm{C}$ & 240 & 0 & - & - & - \\
\hline 13 & & & r.t. & 96 & 69 & 6.7 & 5.5 & 1.2 \\
\hline 14 & & & r.t. & 240 & 88 & 8.1 & 4.4 & 1.9 \\
\hline 15 & \multirow[t]{2}{*}{ A-1B-5 } & & $0^{\circ} \mathrm{C}$ & 96 & 6.7 & 1.9 & 1.3 & 1.4 \\
\hline 16 & & & r.t. & 96 & 70 & 7.5 & 5.4 & 1.4 \\
\hline 17 & \multirow[t]{3}{*}{ A-1B-6 } & & $0^{\circ} \mathrm{C}$ & 240 & 13 & 4.8 & 3.2 & 1.5 \\
\hline 18 & & & r.t. & 96 & 59 & 7.1 & 4.9 & 1.5 \\
\hline 19 & & & r.t. & 240 & 92 & 8.0 & 4.5 & 1.8 \\
\hline
\end{tabular}

${ }^{\mathrm{a}}[\mathrm{M}]_{0}=1.0 \mathrm{~mol} \mathrm{~L}^{-1},[\mathrm{M}]_{0} /[1]_{0}=50$ except for $14,16,19(=100)$, and $6(=50$ in bulk $) .{ }^{\mathrm{b}} \mathrm{r} . \mathrm{t} .=$ room temperature. 


\section{Product Structure by ${ }^{1} H$ NMR}

Although there may be some cyclic or ammonium oligomers, no positive evidence was found for the formation of quaternary ammonium nitrogen atoms in the ${ }^{1} \mathrm{H}$ NMR of the product. Such groups shift the protons on the $\alpha$-carbon of the quaternary nitrogen. The elemental analysis data coincided with the calculated values very well. These results support the linear structure of the polymer. Bulky mesogen-containing subsituent on the nitrogen atoms may prevent attack of tertiary amino groups in the polymer on ammonium propagating species.

Linear polyaziridine was treated with 4-cyano-4'-(4bromobutoxy)biphenyl. The constitutional units of the alkylaated linear polyaziridine with 4-cyano-4'-(4-bromobutoxy)biphenyl (LPA-CN-4) are shown in Figure 2.

The existence of bromine in the elemental analysis suggested the formation of quarternary ammonium salts to some extent. From the elemental analysis of bromine, the fractions of secondary $(x)$ : tertiary $(y)$ : quarternary $(z)$ amino groups were estimated to be 0.31 , $0.64,0.05$, respectively. The ${ }^{1} \mathrm{H}$ NMR spectrum showed that alkylation did not proceed quantitatively leaving some secondary amino groups unreacted $(2.8 \mathrm{ppm}$, $\mathrm{NHCH}_{2}$ ), and that quarterniation occurred to some extent, by the appearance of methylene signals around $3.4 \mathrm{ppm}\left(\mathrm{N}^{+} \mathrm{CH}_{2}\right)$. The ratio of total $\mathrm{H}_{\mathrm{a}}(2 y+4 z)$ to main chain methylene protons $(4 x+6 y+8 z)$ was 0.25 . The calculated value of $(2 y+4 z) /(4 x+6 y+8 z)$ from $x, y$, and $z$ is 0.29 , which coincides well with the observed value by ${ }^{1} \mathrm{H}$ NMR.

In the ${ }^{1} \mathrm{H}$ NMR spectrum of the quarternized product of PA-1B- 4 , the methylene protons at $\alpha$ - and $\beta$-positions to the nitrogen atom shifted to a lower field $(3.1-3.7$ : $\mathrm{N}^{+}-\mathrm{CH}_{2} ; 2.5-3.2: \mathrm{N}^{+}-\mathrm{CH}_{2} \mathrm{CH}_{2}$ ). In the IR spectrum,

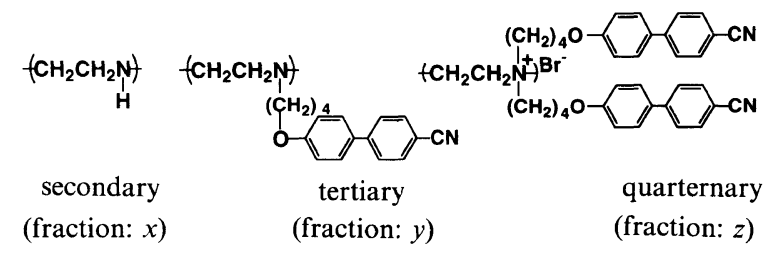

Figure 2. Strucrure of alkylated LPA-CN-4. a broad absorption around $3500 \mathrm{~cm}^{-1}$ indicated the formation of a quarternary salt. Elemental analysis also suggested the formation of a quarternary ammonium salt. The extent of quarternization was estimated to be $64 \%$.

\section{Thermal behavior of monomers and polymer, and Phase Structure by Optical Polarization Micrograph}

Thermal behavior of monomers is summarized in Table II.

The Schlieren texture seen at $76^{\circ} \mathrm{C}$ indicated that this monomer formed a nematic phase on melting. A-CN-5 showed a small peak at $53^{\circ} \mathrm{C}$ and a big peak at $35^{\circ} \mathrm{C}$ in the cooling process, and Schlieren texture was observed at $51^{\circ} \mathrm{C}$ on cooling. The Schlieren texture at $65^{\circ} \mathrm{C}$ in the cooling of A-CN-6 soon disappeared at the temperature. When the cover glass was shifted to one direction, Schlieren texture again appeared and then disappeared, so a homeotropic alignment of the monomer molecules on the glass must have formed.

A-1B-4 shows a small peak at $63^{\circ} \mathrm{C}$, and big peaks at 56 and $52^{\circ} \mathrm{C}$ on cooling. The Schlieren texture at $61^{\circ} \mathrm{C}$ in cooling disappeared shortly. Homeotropic alignment of monomer molecules on the glass must have formed. Homeotropic Schlieren texture of A-1B-5 at $46.5^{\circ} \mathrm{C}$ in cooling from $85^{\circ} \mathrm{C}$ at $5^{\circ} \mathrm{C} / \mathrm{min}$ disappeared at $44^{\circ} \mathrm{C}$, and a marble texture appeared indicating a smectic phase. The compound crystallized at $35^{\circ} \mathrm{C}$. A-1B- 6 crystallized at $56^{\circ} \mathrm{C}$ after the disappearance of Schlieren texture at $64^{\circ} \mathrm{C}$.

Thermal analysis data of polymers are tabulated in Table III. The enthalpy of the transition of PA-CN-4 at $143^{\circ} \mathrm{C}$ was $13.4 \mathrm{~mJ} \mathrm{mmol}^{-1}$ which suggests an isotropic to smectic transition. PA-CN-5 showed two peaks at 185 and $135^{\circ} \mathrm{C}$. Schlieren texture at $152.5^{\circ} \mathrm{C}$ in cooling changed to a mosaic structure at $146^{\circ} \mathrm{C}$. PA-CN-6 showed complex thermal behavior. The mixed Schlieren and batonnet structure at $140^{\circ} \mathrm{C}$ changed to a batonnet and fan structure in $1 \mathrm{~min}$. The fan structure disappeared by annealing at the temperature, and appeared again by sliding the cover glass in one direction. This structure changed to a spherulite structure after prolonged annealing. The exothermic peak at $29^{\circ} \mathrm{C}$ in the heating scan may be attributable to crystallization

Table II. Thermal transition temperature, enthalpy, and entropy of A-CN- $n$ and A-1B- $n$

\begin{tabular}{|c|c|c|c|c|c|c|c|c|c|}
\hline \multirow{2}{*}{ Monomer } & \multirow[t]{2}{*}{ Scanning } & \multicolumn{2}{|c|}{ Transition temp $/{ }^{\circ} \mathbf{C}^{\mathrm{a}}$} & \multicolumn{2}{|c|}{$\Delta H / \mathrm{Jg}^{-1}$} & \multicolumn{2}{|c|}{$\Delta H / \mathrm{kJ} \mathrm{mol}^{-1}$} & \multicolumn{2}{|c|}{$\Delta S / \mathrm{J} \mathrm{mol}^{-1} \mathrm{~K}^{-1}$} \\
\hline & & $T_{1}$ & $T_{\mathrm{i}}$ & $\Delta \mathrm{H}_{1}$ & $\Delta H_{\mathrm{i}}$ & $\Delta H_{1}$ & $\Delta \mathrm{H}_{\mathrm{i}}$ & $\Delta S_{1}$ & $\Delta S_{\mathrm{i}}$ \\
\hline \multirow[t]{2}{*}{$\mathrm{A}-\mathrm{CN}-4$} & Cooling ${ }^{\mathrm{b}}$ & $62(\mathrm{~K} \rightarrow \mathrm{N})$ & 76 & -77 & -2.1 & -22 & -0.6 & -67 & -1.8 \\
\hline & Heating & $82^{\mathrm{d}}$ & & $78^{e}$ & - & 23 & - & 64 & - \\
\hline \multirow[t]{2}{*}{ A-CN-5 } & Cooling ${ }^{\mathrm{b}}$ & $35(\mathrm{~K} \rightarrow \mathrm{N})$ & 53 & -58 & -1.5 & -18 & -0.5 & -58 & -1.4 \\
\hline & Heating ${ }^{\mathrm{c}}$ & $92^{\mathrm{d}}$ & & $64^{e}$ & - & 20 & - & 54 & - \\
\hline \multirow{2}{*}{ A-CN-6 } & Cooling ${ }^{b}$ & $41(\mathrm{~K} \rightarrow \mathrm{N})$ & 66 & -49 & -2.1 & -16 & -0.7 & -50 & -2.0 \\
\hline & Heating ${ }^{\mathrm{c}}$ & 62 & 72 & $57^{\mathrm{e}}$ & - & 18 & - & 54 & - \\
\hline \multirow[t]{2}{*}{ A-1B-4 } & Cooling ${ }^{b}$ & $52,56^{\mathrm{f}}$ & 63 & $-56^{\mathrm{e}, \mathrm{f}}$ & -1.3 & -19 & -0.4 & - & -1.3 \\
\hline & Heating $^{c}$ & $108^{\mathrm{d}}$ & & $65^{\mathrm{e}}$ & - & 22 & - & 58 & - \\
\hline \multirow[t]{2}{*}{ A-1B-5 } & Cooling ${ }^{\mathrm{b}}$ & $35,45,52^{\mathrm{f}}$ & $-g$ & $-50^{\mathrm{e}}$ & - & -18 & - & - & - \\
\hline & Heating ${ }^{c}$ & 54,60 & 71 & $47^{\mathrm{e}}$ & 4.9 & 17 & 1.7 & - & 5.1 \\
\hline \multirow[t]{2}{*}{ A-1B-6 } & Cooling ${ }^{\mathrm{b}}$ & 57 & 65 & -54 & -1.9 & -20 & -0.7 & -60 & -2.1 \\
\hline & Heating ${ }^{c}$ & $75^{\mathrm{d}}$ & - & $63^{e}$ & - & 23 & - & 67 & - \\
\hline
\end{tabular}

${ }^{a} T_{1}$ and $T_{\mathrm{i}}$ are melting (crystallization) and clearing temperatures, respectively. $\quad{ }^{\mathrm{b}}$ First cooling scan. $\quad{ }^{\mathrm{c}}$ Second heating scan. ${ }^{\mathrm{d}} T_{1}$ and $T_{\mathrm{i}}$ not separated. ${ }^{\mathrm{e}}$ Total enthalpy of two transitions. ${ }^{\mathrm{f}}$ Two or more liquid crystalline states suggested. $\mathrm{K}$, crystal; N, nematic. ${ }^{\mathrm{g}} T_{\mathrm{i}}$ possibly to be included in $T_{1}$. 
Table III. Thermal transition temperatures, enthalpy, and entropy of PA-CN- $n$ and PA-1B- $n$

\begin{tabular}{|c|c|c|c|c|c|c|c|c|c|c|}
\hline \multirow{2}{*}{ Polymer } & \multirow{2}{*}{ Scanning } & \multicolumn{3}{|c|}{ Transition temp $/{ }^{\circ} \mathrm{C}^{\mathrm{a}}$} & \multicolumn{2}{|c|}{$\Delta \mathrm{H} / \mathrm{Jg}^{-1}$} & \multicolumn{2}{|c|}{$\Delta H^{\mathrm{b}} / \mathrm{kJ} \mathrm{mol}^{-1}$} & \multicolumn{2}{|c|}{$\Delta S / \mathrm{J} \mathrm{mol}^{-1} \mathrm{~K}^{-1}$} \\
\hline & & $T_{\mathrm{g}}$ & $T_{1}$ & $T_{\mathrm{i}}$ & $\Delta H_{1}$ & $\Delta H_{\mathrm{i}}$ & $\Delta H_{1}$ & $\Delta H_{\mathrm{i}}$ & $\Delta S_{1}$ & $\Delta S_{\mathrm{i}}$ \\
\hline PA-CN-4 & Heating $^{\mathrm{d}}$ & 22 & - & 169 & - & 45 & - & 13 & - & 30 \\
\hline \multirow[t]{2}{*}{ PA-CN-5 } & Cooling ${ }^{\mathrm{c}}$ & 72 & 135 & 185 & -23 & -13 & -7.0 & -3.9 & -17 & -8.5 \\
\hline & Heating ${ }^{d}$ & 68 & 145 & 170 & 22 & 10 & 6.7 & 2.9 & 16 & 6.6 \\
\hline \multirow[t]{2}{*}{ PA-CN-6 } & Cooling $^{\mathfrak{c}}$ & 9 & - & $137,141^{\mathrm{g}}$ & - & $-8.1^{\mathrm{h}}$ & - & -2.6 & -8.4 & - \\
\hline & Heating $^{d}$ & 6 & $29^{i}$ & $140,147^{\mathrm{g}}$ & -11 & $33^{\mathrm{h}}$ & $-3.4^{\mathrm{i}}$ & 11 & -11 & - \\
\hline \multirow[t]{2}{*}{ PA-1B-4 } & Cooling ${ }^{c}$ & 13 & - & 96 & - & -4.0 & - & -1.4 & - & -3.7 \\
\hline & Heating $^{d}$ & 6 & - & 86 & - & 2.8 & - & 1.0 & - & 2.7 \\
\hline \multirow[t]{2}{*}{ PA-1B-5 } & Cooling $^{\mathrm{c}}$ & 38 & $88,97,110^{\mathrm{j}}$ & 154 & $-50^{\mathrm{h}}$ & -9.2 & -18 & -3.3 & - & -7.6 \\
\hline & Heating $^{d}$ & 36 & $105,113,138,148^{\mathrm{j}}$ & $163^{\mathrm{g}}$ & $61^{\mathrm{h}}$ & - & 22 & - & - & - \\
\hline \multirow[t]{2}{*}{ PA-1B-6 } & Cooling $^{c}$ & 8 & 95 & $117^{\mathrm{j}}, 125^{\mathrm{g}}$ & $-41\left(95^{\circ} \mathrm{C}\right)$ & $-5.1^{\mathrm{h}}$ & -15 & -1.9 & -41 & - \\
\hline & Heating & 7 & - & 107 (broad $^{\mathrm{j}}, 131^{\mathrm{g}}$ & - & $60^{\mathrm{h}}$ & - & 22 & - & - \\
\hline LPA-CN-4 & Cooling ${ }^{c}$ & 25 & - & - & - & - & - & - & - & - \\
\hline QPA-1B-4 & Heating $^{\mathrm{e}}$ & 51 & - & 123 & - & 2.2 & - & 0.9 & - & 2.2 \\
\hline
\end{tabular}

${ }^{\mathrm{a}} T_{\mathrm{g}}, T_{1}$ and $T_{\mathrm{i}}$ are glass transition, melting and clearing temperatures, respectively. ${ }^{\mathrm{b}}$ Based on unit mol. ${ }^{\mathrm{c}}$ Second cooling scan. ${ }^{\mathrm{d}}$ Third heating scan at $1{ }^{\circ} \mathrm{C} \mathrm{min}^{-1}$. ${ }^{\mathrm{e}}$ Second heating scan. ${ }^{\mathrm{f}}$ First cooling scan. ${ }^{\mathrm{g}} T_{1}$ and $T_{\mathrm{i}}$ are not separated. ${ }^{\mathrm{h}}$ Total enthalpy of two transitions. ${ }^{i}$ Exothermic peak. Partial crystallization may occurr. ${ }^{j}$ Two or more liquid crystalline states suggested.

a)

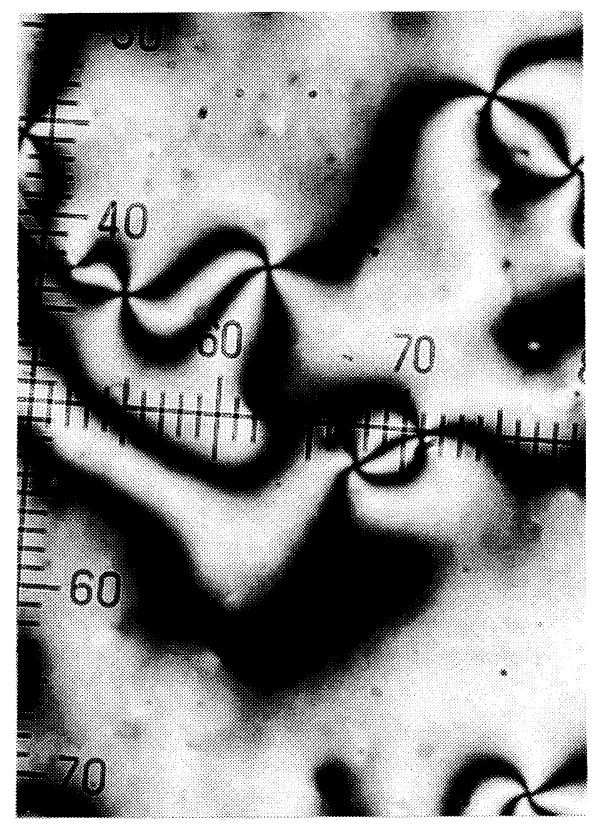

b)

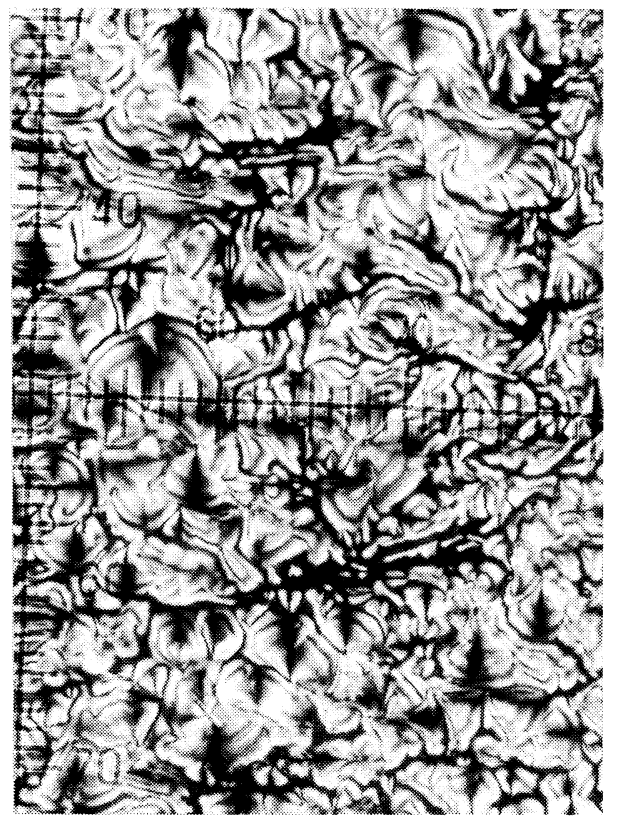

\section{$\stackrel{50 \mu m}{\longrightarrow}$}

Figure 3. Optical polarization micrographs of PA-1B-6: a) annealed at $118.7^{\circ} \mathrm{C}$ for $5 \mathrm{~min}$; b) annealed at $89.7^{\circ} \mathrm{C}$ for $14 \mathrm{~h}$.

and the formation of spherulites.

A nematic phase was formed by PA-1B-4. The Schlieren texture at $135^{\circ} \mathrm{C}$ in cooling of PA-1B-5 changed to an unidetified feather like structure at $113^{\circ} \mathrm{C}$. When the sample was kept at $138^{\circ} \mathrm{C}$ after $30 \mathrm{~min}$, a mixed Schlieren and batonnet texture was observed. This may correspond to the complex thermal behavior seen in DSC. The Schlieren texture of PA-1B-6 at $119^{\circ} \mathrm{C}$ after $1 \mathrm{~min}$ in cooling changed to a Schlieren and fan structure at $90^{\circ} \mathrm{C}$ after $14 \mathrm{~h}$ as shown in Figure 3.
No clear difference could be observed between the glass transition temperatures of PA-CN-4 and LPA-CN4. The extent of substitution may be too low to study the thermal behavior of the polymer, and quarternization of amino group in the polymer backbone strongly influenced the thermal behavior of the polymer. The polymer showed a Schlieren nematic structure by annealing at $98^{\circ} \mathrm{C}$ for $1 \mathrm{~h}$. Transition temperature was elevated $\left(46^{\circ} \mathrm{C}\right.$ for $T_{\mathrm{g}}$ and $24^{\circ} \mathrm{C}$ for $T_{\mathrm{i}}$ compared to the second cooling scan) by quarternization. The transition 
enthalpy became smaller. Quarternization did not necessarily enhance the organization of mesogenic groups as suggested by Ujiie. ${ }^{26-28}$

\section{CONCLUSION}

Aziridine oligomers were found to act as a suitable main chain component for a side-chain liquid crystalline oligomers, with various biphenyl or benzoate derivatives as the mesogenic groups. Strong influence of a glass surface on the liquid crystalline state was observed.

Acknowledgments. This work was supported in part by Grant-in-Aid for Scientific Research (No. 07555595, No. 08455438) and a Grant-in-Aid for Scientific Research in Priority Areas of "New Polymers and Their NanoOrganized Systems" from the Ministry of Education, Science, Sports, and Culture of Japan.

\section{REFERENCES}

1. N. A. Plate and V. P. Shibaev, Ed., "Comb-Shaped Polymers and Liquid Crystals," Plenum, New York, N.Y., 1987.

2. C. B. McArdle, Ed., "Side Chain Liquid Crystal Polymers," Chapman and Hall, New York, N.Y., 1989.

3. A. A. Collyer, Ed., "Liquid Crystal Polymers: From Structures to Applications," Elsevier, Barking, 1992.

4. N. A. Plate, Ed., "Liquid-Crystal Polymers," Plenum, New York, N.Y., 1993.

5. H. Finkelmann, H. Ringsdorf, and J. H. Wendorff, Makromol. Chem., 179, 273 (1978).

6. H. Finkelmann, M. Happ, M. Portugal, and H. Ringsdorf, Makromol. Chem., 179, 1978 (1978).

7. V. Percec and B. Hahn, Macromolecules, 22, 1588 (1989).

8. C. T. Imrie, F. E. Karasz, and G. S. Attard, Macromolecules, 28, 3617(1995). spacer

9. K. Shiraishi and K. Sugiyama, Chem. Lett., 1697 (1990).
10. P. L. Magagnini, F. Andruzzi, and G. F. Benetti, Macromolecules, 13, 12 (1980).

11. J. J. Mallon and S. W. Kantor, Macromolecules, 23, 1249 (1990).

12. C. T. Imrie, F. E. Karasz, and G. S. Attard, Macromolecules, 27, 1578 (1994).

13. V. Percec, Makromol. Chem., Macromol. Symp., 13/14, 397 (1988).

14. B. Durairaj, E. T. Samulski, and T. M. Shaw, Macromolecules, 23, 1229 (1990)

15. R. E. Singler, R. A. Willingham, R. W. Lenz, and A. Furukawa, Macromolecules, 20, 1728 (1987).

16. M. Kojima and J. H. Magill, Polymer, 30, 579 (1989).

17. H. R. Allcock and C. Kim, Macromolecules, 23, 3881 (1990).

18. F. Andruzzi, D. Lupinacci, and P. L. Magagnini, Macromolecules, 13, $15(1980)$.

19. V. Percec, J. Polym. Sci., Polym. Chem., 25, 2269 (1987).

20. V. P. Shibaev, Polym. Bull., 20, 249 (1993).

21. E. Akiyama, M. Otomo, and Y. Nagase, Macromol. Chem. Phys., 196, 3391 (1995).

22. D. Taton, A. L. Borgne, N. Spassky, and C. Noel, Macromol. Chem. Phys., 196, 2941 (1995).

23. Y. Kawakami and K. Takahashi, Polym. Bull., 25, 521 (1991).

24. Y. Kawakami, K. Takahashi, and H. Hibino, Macromolecules, 24, 4531 (1991)

25. Y. Kawakami, K. Takahashi, S. Nishiguchi, and K. Toida, Polym. Int., 31, 35 (1993).

26. S. Ujiie and K. Iimura, Kobunshi Ronbunshuu (in Japanese), 48, 719 (1991).

27. S. Ujiie and K. Iimura, Macromolecules, 25, 3174 (1992).

28. S. Ujiie and K. Iimura, Polym. J., 25, 347 (1993).

29. Y. Kawakami, K. Toida, and Y. Ito, Macromolecules, 26, 1177 (1993).

30. Y. Kawakami and K. Toida, Macromolecules, 28, 816 (1995).

31. Y. Kawakami, M. Ichitani, H. Kunisada, and Y. Yuki, Polym. $J$. , in press.

32. T. Saegusa, H. Ikeda, and H. Fujii, Polym. J., 3, 35 (1972).

33. T. Saegusa, H. Ikeda, and H. Fujii, Macromlecules, 5, 108 (1972).

34. A. T. Bottini and J. D. Roberts, J. Am. Chem. Soc., 80, 5203 (1958).

35. E. J. Goethals, E. H. Schcht, P. Bruggeman, and P. Bossaer, Am. Chem. Soc., Symp. Ser., 59, 1 (1977). 